\title{
On the Contingency of Universalism
}

\author{
Claudio Calosi ${ }^{1}$ (D)
}

Received: 3 September 2020 / Accepted: 21 June 2021

(c) The Author(s) 2021

\begin{abstract}
The paper presents different arguments against the necessity of mereological universalism. First, it argues that they are examples of a much more general argumentative structure. It then contends that some of these arguments cannot be resisted by distinguishing different variants of universalism that have been recently proposed in the literature-in contrast with recent suggestions to the contrary. Finally, it provides different ways to resist such contingentist arguments on behalf of universalists.
\end{abstract}

\section{Introduction}

There is a hotly debated argument against the necessity of mereological universalism, roughly the view that a non-empty collection of objects composes a further object, the so-called Junk argument. The argument allegedly establishes that mereological universalism is at best contingently true-and thus composition is contingent as well. It was first presented in Bohn (2009a), and then criticized in Contessa (2012) and Watson (2010). Bohn (2010) and Cotnoir (2014) defended it. Recently Smith (2019) criticized both the argument and Cotnoir's defense, concluding that

[T] he proponent of contingent composition will have to look elsewhere for an argument in favor of his position (Smith, 2019: 55).

Here, I will look elsewhere. I will first (Sect. 2) argue that the Junk argument is but one example of what I call Contingency Arguments. These arguments display a common structure that features an Incompatibility Premise and a Possibility Premise. I will then look at a criticism of the Incompatibility Premise of the Junk argument originally due to Contessa (2012) and recently defended in this journal in Smith (2019). I will argue that their defense does not work against the Contingency Arguments more in general (Sect. 3). The provisional conclusion is twofold: (i) the necessary truth of universalism is still threatened, pace Contessa and Smith; (ii) the real culprit is not the Incompatibility Premise, but rather the Possibility Premise.

Claudio Calosi

claudio.calosi@unige.ch

1 Department of Philosophy, University of Geneva, Geneva, Switzerland 
I will then go on to suggest ways to resist such a premise on behalf of universalists (Sect. 4). ${ }^{1}$

\section{The Contingency Arguments}

\subsection{The Structure}

The Contingency Arguments share a very simple, general, common structure. Or so I am about to argue. They are two-premises arguments for the conclusion that universalism is at best contingently true, or more briefly, universalism is not necessary. I will first lay out the general argumentative structure and then simply show that the arguments that will be the focus of this paper, the hotly debated Junk argument in primis, do conform to such a structure. In general, the Contingency Arguments feature an Incompatibility Premise to the point that universalism is incompatible with the existence of certain possible worlds, and a Possibility Premise, to the point that there are certain possible worlds. In light of this, I suggest we parse the Contingency Arguments as follows:

Incompatibility Premise. If universalism is necessary, then there is no possible world $w$ such that $w$ is $\phi$, for some condition $\phi ;^{2}$

Possibility Premise. There is a possible world $w$ such that $w$ is $\phi ;^{3}$

Conclusion. Universalism is not necessary.

In the next sections I will formulate the Contingency Arguments in such a way as to be clear that, upon inspection, they are examples of the general structure just laid out. Universalism is usually charged of being too liberal, too inclusive, in that it countenances metaphysical monstrosities such as trout-turkeys in its ontology. In effect, according to universalism such metaphysical monstrosities are actual, and therefore possible. ${ }^{4}$ By contrast, the charge of the Contingency Arguments is that universalists are too restrictive. They suffer from a form of modal blindness insofar as they discard metaphysical possibilities that should not be discarded.

\footnotetext{
1 From now on, by "universalists" I mean those who endorse the claim that universalism is necessary.

${ }^{2}$ I will take this claim to be equivalent-in a loose sense- to the following claim: the necessity of universalism and the possibility of $\phi$-worlds are incompatible. Hence the label: Incompatibility Premise. Their strict logical equivalence will depend on what notion of implication is at stake.

3 I will understand modality in terms of possible worlds. Hence the label: Possibility Premise.

4 The trout-turkey example is in Lewis (1991). Examples of such a charge abound. I refer the reader to references mentioned in Varzi $(2016, \S 4.5)$.
} 


\subsection{The Junk Argument}

Let us then look at the much debated Contingency Argument, the Junk argument. Say that a possible world $w$ is junky iff everything in $w$ is a proper part of something (else) in $w .{ }^{5}$ We obtain the argument by letting $\phi=$ "being junky":

(1) If universalism is necessary, then there is no possible world $w$ such that $w$ is junky;

(2) There is a possible world $w$ such that $w$ is junky;

(3) Universalism is not necessary.

Both Contessa (2012) and Smith (2019) attack the Incompatibility Premise (1) of the Junk argument. Watson (2010) attacks the Possibility Premise instead, whereas Bohn (2010) defends it. Cotnoir (2014) defends the Incompatibility Premise. ${ }^{6}$ In Sect. 3 I will argue that, interestingly enough, the criticism in Contessa (2012) and its recent defense in Smith (2019), do not work against the Contingentist Arguments in the rest of this paper.

\subsection{The Exact Number Argument and the Even Number Argument}

Here is a first contingentist argument, which I will label the Exact Number argument. It is obtained by letting $\phi=$ "being such that there are exactly $n$ objects in $w$ ". The argument is already in Comesaña (2008), though it is surprisingly neglected in the literature on the Junk argument. The justification I will provide for the Incompatibility Premise of the argument is different from that in Comesaña (2008) in that it is far more general. This will play a role in putting forth a novel Contingency Argument in the rest of the section. To the argument:

(4) If universalism is necessary, then, for some natural number $n$, there is no possible world $w$ such that there are exactly $n$ objects in $w$;

(5) For any natural number $n$, there is a possible world $w$ such that there are exactly $n$ objects in $w$;

(3) Universalism is not necessary.

Clearly the burden of the argument lies in the defense of the Incompatibility Premise (4) and the Possibility Premise (5). I will mostly focus on (4) here, and leave

\footnotetext{
5 A formal definition is in footnote 7.

${ }^{6}$ See also the discussion in Cotnoir and Varzi (Forthcoming, §5.5).

${ }^{7}$ Let $\sqsubseteq$ be the primitive meroelogical relation of parthood. Define (i) proper parthood: $\quad x \sqsubset y \equiv x \sqsubseteq y \wedge x \neq y$, (ii) Overlap $\quad x \circ y \equiv \exists z(z \sqsubseteq x \wedge z \sqsubseteq y)$; (iii) Fusion $F_{\phi} z \equiv \forall x(\phi(x) \rightarrow x \sqsubseteq z) \wedge \forall y(y \sqsubseteq z \rightarrow \exists x(\phi(x) \wedge x \circ y)$. Junk is then defined as: $\forall y \exists x(y \sqsubset x)$. The arguments in the paper take parthood to be a partial order that obeys the so-called Weak Supplementation principle: $x \sqsubset y \rightarrow \exists z(z \sqsubseteq x \wedge \neg y \circ z)$. Universalism in general, together with such mereological principles entails mereological extensionality-see Varzi (2009). For a discussion about Weak Supplementation and mereological extensionality in the present context see Cotnoir (2014).
} 
the discussion of (5) to Sect. 4. Here is an argument in favor of (4). Given $m$ simples, ${ }^{8}$ universalism entails that there are exactly $2^{m}-1$ objects. To see this, notice that given $m$ simples, universalism entails there are all possible mereological fusions of such simples. Clearly, all such possible fusions are the mereological counterparts of all possible subsets of the set $S$ containing the original $m$ simples. The number of fusions of simples is thus equal to the cardinality of the power set $2^{S}$ of $S$, that is $2^{m}$, minus 1 . Why minus 1 ? In the mereological case, the number is $2^{m}-1$ because it is assumed that there is no null object, an object that is part of everything elsenull object being the mereological counterpart of the empty set. ${ }^{9}$ This entails that there is no possible world $w$ where $n=2, n=4, n=6$, and so on. This justification in favor of (4) is about to play a role. ${ }^{10}$

An attentive reader probably noticed two things. First, (5) can be substantially weakened, by replacing instances of $n$, and sticking to those instances, without committing to the universal claim in (5). Second, an interesting pattern emerges. Once this pattern is recognized, one can put forward a different, novel argument, which I will label the Even Number argument, which is obtained by letting $\phi=$ "being such that there is an even number of objects in $w "{ }^{11}$

(6) If universalism is necessary, then there is no possible world $w$ such that there is an even number of objects in $w$;

(7) There is a possible world $w$ such that there is an even number of objects in $w$;

(3) Universalism is not necessary.

\footnotetext{
${ }^{8}$ A simple is an object with no proper parts: $S(x) \equiv \neg \exists y(y \sqsubset x)$.

9 This is already noted in Simons (1987: 17). The null object is defined as: $N(x) \equiv \forall y(x \sqsubseteq y)$. It is usually assumed that the null object does not exist because, in the presence of Weak Supplementation (see Footnote 7), the existence of the null object entails that the only finite models are models with just one object, the null object itself. To see this, assume there is at least an object $o$ that is distinct from the null object. By definition, the null object is part of $o$, and therefore a proper part of it. Weak Supplementation entails there is a part of $o$ which is disjoint from the null object. But there cannot be any such disjoint part. The null object is part of everything, and therefore overlaps everything. Contradiction. Clearly this will not help the universalist cause.

${ }^{10}$ This argument in favor of the Incompatibility Premise could arguably be resisted by endorsing the controversial thesis known as Composition is Identity, roughly the view that a fusion is strictly identical to its parts considered collectively - for a recent introduction see Baxter and Cotnoir (2014). Two things are worth noting. First, one may want to endorse universalism without thereby committing herself to the stronger and controversial thesis of Composition is Identity. Second, it is unclear whether Composition is Identity is compatible with universalism. For instance, Calosi (2016) and Calosi (2018) argue that it is actually logically equivalent to mereological nihilism.

${ }^{11}$ A referee for this journal pointed out to me that Sorensen (2003) explicitly recognizes this "odd consequence" of universalism - though Sorensen does not draw any conclusions from it. Here is the relevant passage:

The Structure of Appearances implies an answer to "Is the number of individuals in the universe odd or even?" Since there are only finitely many atoms and each individual is identical to a combination of atoms, there are exactly as many individuals as there are combinations of atoms. If there are $n$ atoms, there are $2^{n}-1$ combinations of individuals. No matter which number we choose for $n, 2^{n}-1$ is an odd number. Therefore, the number of individuals in the universe is odd! (Sorensen, 2003: 362).
} 
As before, I will focus here on (6) and leave the discussion of (7) to Sect. 4. The argument in favor of the Incompatibility Premise (6) is spectacularly simple. $2^{m}=\underbrace{2 \times 2 \times \cdots \times 2}_{m \text {-times }}$ which is clearly even, so that $2^{m}-1$ is indeed odd. ${ }^{12}$

In light of the above, the Incompatibility Premises (4) and (6) seem compelling. If so, universalists should take a closer look at the Possibility Premises (5) and (7). This is what I will do in Sect. 4. Before that however, we should linger on the Incompatibility Premises a little longer, if only because it was that premise of the Junk argument that received most attention. In the next section I am going to argue that the arguments against the Incompatibility Premise of the Junk argument in Contessa (2012) and Smith (2019) are ineffective against the Incompatibility Premises of both the Exact Number and the Even Number argument.

\section{The Contingency Arguments and The Incompatibility Premise}

As I said, Contessa (2012) and Smith (2019) criticize the Incompatibility Premise (1) of the Junk argument. Universalism, so the thought goes, can be formulated in two different ways, namely:

Strong Universalism. Any collection of objects has a mereological fusion.

Weak Universalism. Any two objects have a mereological fusion.

Contessa and Smith claim that the Incompatibility Premise is true if universalism is formulated as Strong Universalism, but false if it is formulated as Weak Universalism. ${ }^{13}$ Briefly, the argument is as follows. Strong Universalism entails the existence of the universe - or the totality object in Contessa's own words-that is, something of which everything is part. But junky worlds are incompatible with the existence of the universe-just check the definition in footnote 7. Thus, Strong Universalism is indeed incompatible with junk. By contrast, Weak Universalism does

\footnotetext{
12 The Even Number Argument crucially depends on further mereological principles, such as Weak or Strong Supplementation-as I briefly mention in footnote 7. Let us see this in more detail. Here is, again, Weak Supplementation: $x \sqsubset y \rightarrow \exists z(z \sqsubseteq y \wedge \neg(x \circ z))$. If one gives up Weak Supplementation, one gets the following 2-object model: $x$ with a single proper part $y$. And here is Strong Supplementation: $\neg y \sqsubset x \rightarrow \exists z(z \sqsubseteq y \wedge \neg(x \circ z))$. It is well-known that in the presence of Strong Supplementation one can prove Extensionality of proper parts, to the effect that if $x$ and $y$ have the same proper parts they are identical. Suppose one now gives up Strong Supplementation and Extensionality along with that. Then the following is a possible 4-object model: $x$ and $y$ are atoms that compose two distinct objects $z$ and $w$. As I pointed out already Varzi (2009) argues that Universalism together with Weak Supplementation entails Extensionality. One way to resist the argument would then be to give up Weak Supplementation. Thanks to an anonymous referee here.

13 In the light of extensionality-see footnote 7 -we can then introduce a general fusion operator with the use of the Russellian definite description operator $\sigma x(\phi(x)) \equiv \imath z \forall x(\phi(x) \rightarrow x \sqsubseteq z) \wedge \forall y(y \sqsubseteq z \rightarrow \exists x(\phi(x) \wedge x \circ y)$. In particular the general fusion operator is useful to define Binary Sum as: $x+y=\sigma z(z \sqsubseteq x \vee z \sqsubseteq y)$. With this in place Strong Universalism becomes: $\exists x\left(\phi(x) \rightarrow \exists z\left(F_{\phi} z\right)\right.$, whereas Weak Universalism becomes: $\forall x \forall y \exists z(z=x+y)$.
} 
not entail the existence of the universe. Therefore, Weak Universalism is compatible with junk. In effect, Smith explicitly claims that Weak Universalism

[I]s a viable candidate to be a necessary principle of composition (Smith, 2019: 42).

It is interesting in and of itself that the arguments in Sect. 2.3, if on the right track, will also provide a reason against this last contention. That is, if they are on the right track, the arguments also establish that Weak Universalism is contingent as well. ${ }^{14}$

Now, as they stand, both the Exact and the Even Number argument in Sect. 2.3 seem to be vulnerable to the following objection. Both in the formulations of the Incompatibility Premises and in their defenses there is no distinction between Strong and Weak Universalism. And this distinction was key-allegedly-to resist the Junk argument. One should distinguish the two variants of universalism in the Exact and the Even Number arguments as well. That is absolutely correct. But it should also be clear why distinguishing between Strong and Weak Universalism cannot help in the case at hand. As we saw, the crucial difference between Strong and Weak Universalism is that the former but not the latter entails the existence of the universe. But the existence of the universe is irrelevant for the Exact and Even Number arguments. No reference, neither explicit nor implicit, is ever made in such arguments to the universe. In effect, for any world $w$ with a finite collection of $m$ simples, Strong and Weak Universalism are on a par. They both entail that there is exactly a finite number $2^{m}-1$ of objects in $w$-the argument for this claim being the one immediately following the Exact Number argument. This shows two things. First, those who endorse the Possibility Premises (5) and (7) can put forward an argument against the necessity of universalism which is fairly general. Second, they can also claim that Weak Universalism is contingent after all, pace Smith (2019). ${ }^{15}$ One may be content with contingentism about composition. ${ }^{16}$ The others should recognize that universalism poses constraints on possible cases of composition, and direct their attention to the real culprits, the Possibility Premises. I now turn to this.

\section{The Contingency Arguments and the Possibility Premises}

One of the upshots of the last section is that there are still two standing Contingency Arguments, the Exact Number and Even Number argument. Furthermore, I argued that the case in favor of the Incompatibility Premises of such arguments is compelling-I will return to this. Universalists need to take issue with the Possibility Premises. Let me first indulge in a quick consideration that I find not completely

\footnotetext{
14 Naturally the conclusion holds only if the relevant Possibility Premises are endorsed.

15 The same goes for other candidates that are discussed yet not endorsed in the literature, for example the principle discussed in Bohn (2009a) to the point that only finite collections of objects have a fusion. It will also apply to the proposal in Vogt and Werner (MS) which defends the view that only collections up to certain cardinalities have fusions.

16 Defenders include Rosen (2006), Cameron (2007), Bohn (2009a, 2009b), and Parsons (2013).
} 
unconvincing - and will play a role later on. The Contingency Arguments are modus tollens arguments. But, echoing Putnam, ${ }^{17}$ "one philosopher's modus tollens is another philosopher's modus ponens". That is, one can argue along the following lines:

Incompatibility Premise. If universalism is necessary, then there is no possible world $w$ such that $w$ is $\phi$, for some condition $\phi$;

Necessity Premise. Universalism is necessary;

Conclusion. There is no possible world $w$ such that $w$ is $\phi$.

Clearly, the point would be to have independent arguments in favor of either the Possibility or the Necessity premises and evaluate their respective strengths. Here are some possible arguments in favor of the Necessity Premise above. Universalism is a metaphysical thesis. Metaphysical theses are, if true, necessarily true. ${ }^{18}$ Thus, universalism is necessary - if true at all. Another somewhat related argument appeals to metaphysical laws. ${ }^{19}$ Universalism is a metaphysical law. Metaphysical possibility is compatibility with metaphysical laws. ${ }^{20}$ There is no possible world $w$ such that $w$ is $\phi$, for every $\phi$ in the Possibility Premises. I don't mean to endorse the arguments. Nor do I need to. As it will be clear soon enough it is their sheer existence and availability that is relevant in the present context. In effect, I don't want to discuss this or other possible arguments in favor of the Necessity Premise at any length. My intention is rather to focus on the arguments for the Possibility Premises of the standing Contingency Arguments. ${ }^{21}$ And I will argue that none of them are compelling.

Let me start from the Possibility Premise (5). Comesaña (2008) writes that it

[D]erives from our particular pre-theoretical judgments that there could have been exactly two things, three things, and... (Comesaña, 2008. 34).

Given that, to my knowledge, the Even Number argument has never been put forth in the literature there is no argument in favor of its Possibility Premise. And yet, I suspect that many would consider it the most plausible Possibility Premise of them all. What is this metaphysical privilege bestowed upon odd numbers, this oddity of being odd? But, as I said, this is just a suspicion. Be that as it may, we may look at arguments for the Possibility Premise (2) of the Junk argument to construct a similar argument in favor of (7). Bohn (2009b) and Bohn (2010) contend that junky worlds pass a three-step possibility test:

\footnotetext{
${ }^{17}$ See Putnam (1994: 280).

${ }^{18}$ Even critics of this last claim admit that "[i]t is near orthodoxy that whichever of these sorts of metaphysical claims is true is necessarily true" (Miller, 2009: 23).

${ }^{19}$ For a defense of the general structure of the argument-not its application to the case at hand-see Schaffer (2017).

${ }^{20}$ Note that this is exactly what we do in case of physical possibility. We characterize it in terms of compatibility with laws of nature.

${ }^{21}$ I will not discuss the Possibility Premise of the Junk argument, simply because I am not sure I have much to add to what has been already said specifically about that premise-see e.g. Watson (2010) and Bohn (2010). However, many of the points I will make will carry over, mutatis mutandis, to the Junk argument as well.
} 
[I] argue (i) that junky worlds are (positively) conceivable and (ii) that junky worlds are logically consistent (in the sense of there being mereological models of them involving no controversial mereological principles) and (iii) that their possibility has been defended by such serious thinkers (Bohn, 2010: 296297).

He claims that the conjunction of (i) conceivability, (ii) consistency, and (iii) advocacy, "provides prima facie evidence for the possibility of junky worlds (Bohn, 2010: 297)". ${ }^{22}$ Finally, Bohn contends, when faced with the fact that junky worlds pass the three-step possibility test above, universalists cannot simply assert the necessity of universalism, and should therefore try to explain the counterexamples-i.e. the problematic worlds-away (more on this later on). ${ }^{23}$ In light of this, one can construct the following argument for the Possibility Premise of the Even Number argument-and for the Possibility Premise of the Exact Number argument for that matter: possible worlds in which there is an even number of objects pass the three-step possibility test. And this is prima facie evidence for their metaphysical possibility. An infamous example of such a world is arguably Max Black's two-sphere world in Black (1952). On the face of it, the two-spheres world is populated only by two simple iron spheres. Black's world seems to pass the three-step possibility test with flying colors. It has been conceived and advocated, and it is consistent. We thus seem to have two arguments in favor of the Possibility Premises: one argument from pre-theoretical intuitions, and one broad conceivability argument from the three-step possibility test mentioned above. Faced with these arguments, one question is whether universalists can explain the problematic possible world away as Bohn would put it. By "explaining it away", I take it, Bohn (2010: 298) means that universalists should explain why, worlds that at first sight provide counterexamples to the necessity of universalism, do not really do so at a closer scrutiny. I will get to this shortly.

Before that, I think it is important to realize that explaining away-in the sense delineated above - is in fact not the only strategy that is available to universalistspace Bohn. They can simply push back on his insistence that one should explain the problematic words away, for it is explicitly predicated on the premise that if universalists don't explain the problematic worlds away, then they are simply asserting-Bohn's own words - the necessity of universalism. But as we saw, this is not the case. Universalists have themselves independent arguments for their Necessity Premise. We saw two of them, from the nature of metaphysical theses, and from a

\footnotetext{
22 A minor point. Bohn (2009a, b) claims that he has adopted this three-step possibility test from Schaffer (2003). However in Schaffer (2003) one finds (i) and (ii), but (iii) is substituted with (iv): physical seriousness. Here is Schaffer:

[T]he Leibnizean picture of infinite division passes excellent texts for being possible: it is (a) conceivable, (b) logically consistent and (c) physically serious (Schaffer, 2003: 501).

One may find this difference important insofar as the physical seriousness of junky worlds has not being argued for. I will not push this line of argument here, for I believe that Bohn is right in "discarding" physical seriousness, at least insofar as this is constructed narrowly. If one is committed to a distinction between physical and metaphysical possibility, and endorses the somewhat standard stance that physically possible worlds are just a subset of metaphysically possible worlds, there is little reason to restrict the attention to "physically serious" worlds-whatever this means.

23 See Bohn (2010: 298).
} 
certain conception of metaphysical laws and metaphysical possibility. So, they really don't have to explain the worlds away. They could simply claim that at this stage in the dialectic, it is a matter of (i) weighting arguments in favor of the necessity of universalism against the plausibility of a pre-theoretical intuition on the one hand, and (ii) weighing arguments in favor of the necessity of universalism against the three-step possibility argument on the other. As for (i), I simply have to confess that I am not convinced about the use of intuitions to adjudicate metaphysical questions. In fact, one may simply hold that an argument always trumps an unsupported intuition. In any case, I will return to the pre-theoretical intuition argument later on. As of now, I want to focus on (ii). Here my contention is that, on the face of it, the case from the three-step possibility argument is rather weak. As Cotnoir writes:

I do not think Bohn's three criteria are sufficient for (or even provide good evidence for) metaphysical possibility (Cotnoir, 2014: 650).

This is because the three-step possibility test is itself rather weak. ${ }^{24}$ In the absence of any details about the notion of conceivability at hand, it is way too easy to pass the test. And those who endorsed the Possibility Premises have provided no such details, despite the enormous body of work dedicated to the issue. ${ }^{25}$ Serious philosophers have conceived and advocated all sorts of situations and worlds: against pluralism worlds with only one object, against materialism worlds with disembodied souls, against sortal essentialism worlds in which humans become animals, trees, even abstract objects like melodies, and so on. My bet is that for any claim that is allegedly necessary, you will find serious philosophers that conceived and advocated situations that provide a counterexample to it. As Hill puts it:

[S]imple, undisciplined conceiving is not a reliable test for possibility. On the present account of conceiving, it is possible to conceive of anything, including logical contradictions (Hill, 2016: 328).

Michels (2020) voices the same attitude, and provides an example:

[W]ithout any qualification of what we mean by conceivability, there is no way to exclude the conceivability of metaphysically impossible states of affairs, such as that of water being an element. Given a naïve, unqualified notion of conceivability, the conceivability of a state of affairs does not entail its metaphysical possibility (Michels, 2020: 7).

To further stress the point, those who endorsed the Possibility Premises of the Contingentist Arguments because they were persuaded by broad conceivability arguments have provided us no explicit detail to the point that the conceivability in question is substantially different from the simple, unqualified, naïve conceivability Hill and Michels are warning us against. In effect, Hill continues:

\footnotetext{
${ }^{24}$ As a matter of fact, I think that Schaffer's original three-step possibility test- the one in footnote 20 is much harder to pass.

25 As a point of entry in this too-vast-to-mention literature, see Szabo-Gendler and Hawthorne (2002) and references therein.
} 
If we are to have a reliable test for possibility, we must rely instead on what I will call constrained conceiving-conceiving that is compatible with the laws of logic, the principles that are constitutive of concepts, and any other propositions that are assumed to be necessary in the relevant context (Hill, 2016: 328, italics added).

But this is clearly grist for the universalist mill. For the universalist has already provided arguments for her Necessity Premise. She could simply claim that, at this stage, it has not be shown that the conceivability at hand is Hill's constraint conceivability — and thus not a reliable guide to (metaphysical) possibility. She could actually push the point further: given her arguments for the Necessity Premise one of the proposition that should be considered necessary in the relevant context is exactly universalism.

I am prepared to concede that at this point we should give the contingentists the opportunity to fill in some details about conceivability in order to beef up their case for the Possibility Premises. In what follows I will argue that plausible ways to fill in such details will also give the universalist a leeway to explain the problematic worlds away, as per Bohn's request.

The argument starts by recognizing that conceiving, whatever it is, is a mental representation. And the standard view has it that ${ }^{26}$

[T]here are two candidate codings for mental representations (one of them being, according to some, reducible to the other): the linguistic and the pictorial (Berto and Shoonen, 2018: 2697).

Now, if the conceivability at stake in the Possibility Premises is a question of forming a linguistic representation, then it is very plausible that we can conceive the impossible. We can have a linguistic representation of logical contradictions, or a linguistic representation according to which water is an element. ${ }^{27}$ It is noteworthy that Berto and Shoonen (2018) almost equate this linguistic notion of conceivability with Hill's "simple, undisciplined" conceivability. This kind of conceivability is not a guide to metaphysical possibility exactly because, in this very broad and simple sense, we can conceive the impossible. This leaves a broadly pictorial notion of conceivability. Berto and Shoonen (2018) relate this pictorial notion of conceivability with Chalmer's positive conceivability, ${ }^{28}$ Yablo's imaginability, ${ }^{29}$ and Hill's

\footnotetext{
26 See e.g. Paivio (1986).

27 For a sustained argument see Berto and Shoonen (2018), especially Sect. 4.

28 See Chalmers (2002). To be fair, I should register that Bohn (2010: 296) claims that junky worlds are "(positively) conceivable". But he does not relate this to Chalmer's positive conceivability.

${ }^{29}$ In the absence of defeaters. See Yablo (1993).
} 
constraint conceivability. It is important to note that they all have some sympathies for the view that this kind of conceivability is a somewhat reliable guide to possibility. I am going to concede this much - a very generous concession indeed. ${ }^{30}$ This is because I think that, even if universalists concede this, they will have a way to explain the problematic worlds away. Here is why.

Suppose I were to ask you to picture a world $w_{1}$ with only two spheres-to stick to Black's infamous example - and to picture a world $w_{2}$ with the same two spheres together with their mereological sum. You would picture "the same world". Try it. Draw what you pictured, that is, draw $w_{1}$ and $w_{2}$. Now compare the drawings. As far as picturing goes, there is nothing in $w_{1}$ that is not in $w_{2}$. In light of this I now ask you: how can you be sure that you pictured $w_{1}$ instead of $w_{2}$ ? But note that this is crucial. For $w_{2}$ clearly does not constitute a counterexample to the necessity of universalism. In general, a world with $m$ simples and a world with $m$ simples together with all their the mereological fusions are pictorially indistinguishable. This amounts, I contend, to explain the problematic world away. When you say that you conceived - that is, you pictured-of a world in which there are only two spheres (i.e. $w_{1}$ ), the universalist replies that you really conceived - that is, you pictured-of a world in which there were two spheres and their sum (i.e $\left.w_{2}\right) .{ }^{31}$

This still leaves the pre-theoretical intuition argument open-at least for those who are not skeptical about the use of intuitions in metaphysics. To conclude the paper I offer one final strategy to resist the Contingency Arguments on behalf of

\footnotetext{
30 Skeptics about conceivability are easy enough to find: the classic is arguably van Inwagen (1998). Fiocco (2007) is a recent example.

31 Here is a possible rejoinder on behalf of contingentist. The argument assumes that all there is to a mental picture is its qualitative content. One can challenge such an assumption. For example, developing an insight from Kung (2010) on imagination one can hold that a mental picture includes assignments on top of a qualitative content. According to Kung an assignment is a

[L]oose way of referring to all informations captured by labels and stipulations. Any piece of this information is an assignment (Kung, 2010: 625)

The thought is that a picture of $w_{1}$ and $w_{2}$ do not differ in their qualitative content but they differ in their assignments. In $w_{1}$ you have an assignment for each of the two sphers, say $s_{1}$ and $s_{2}$, whereas in $w_{2}$ you have the same assignments for the spheres together with an assignment for their sum, say, $s_{1}+s_{2}$. This is already going far and beyond what the contingentists themselves have ever provided. And yet it would not take us very far. For, as Kung himself notes an

[A]n imagining that $\mathrm{P}$ will not be evidence that $\mathrm{P}$ is possible if $\mathrm{P}$ 's truths in the imagined situation follows from the assignments alone. The reason is that stipulations and labels [i.e. the assignments] are virtually unconstrained, and what minimal constraints there are have no modal epistemological value (Kung, 2010: 634).

In other words: what follows from the assignments alone is no guide to metaphysical possibility. And in this case, whether the picture at hand is a picture of $w_{1}$ rather than $w_{2}$ does follow from the assignments alone, their qualitative content being the same. Hence it is of no help to secure the modal claim of the relevant Possibility Premise. Naturally, Kung's own theory of imagination is but a possible one, though one that was at first sight useful to contingentists. I am not claiming there are cannot be other theories of "picturability" that might prove more useful in the hands of contingentists. But it's up to them to provide these details.
} 
universalists-yet I do not want to claim that this is the only strategy available. The strategy I have in mind starts by recognizing with Varzi that

[W] e quantify over everything, since the meaning of "everything" is set by the domain of the quantifiers; yet counting is selective. And we may set different standards for counting, but we must avoid omissions and repetitions. ${ }^{32}$ (Varzi, 2010: 287 , italics added). ${ }^{33}$

Once we acknowledge a distinction between existence and (selective) counting, so the thought goes, two readings of the Possibility Premise(s) become available. Let me clearly disambiguate these two readings-I will mostly discuss a particular instance of (5) for the sake of simplicity:

(5-Existence) For any natural number $n$, there is a possible world $w$ such that the exact number of objects that exist in $w$ is $n$;

(5-Count) For any natural number $n$, there is a possible world $w$ such that, under a given counting policy, counting the objects in $w$ results in a count of exactly $n$ objects.

I will first argue that, if (5) is read as (5-Count), then universalists can recognize the existence of the allegedly problematic worlds. In effect, Varzi himself suggests different counting policies that are compatible with the existence of such worlds. The first one is any counting policy compatible with what Varzi calls the Minimalist View: $:^{34}$

(M) An inventory of the world is to include an entity $x$ if and only if $x$ does not overlap any other entity $y$ that is itself included in that inventory. Varzi (2010: 285).

There is clearly a counting policy compatible with the Minimalist View (M) such that, e.g. counting the objects in Black's world, results in a count of exactly 2 objects. First, count the 2 spheres. Then, notice that according to the Minimalist View, once you counted the 2 spheres, you should not count anything else, for everything else overlaps the spheres. Most importantly, you should not count their sum. Thus, universalists can account for the truth of (5), if (5) is read as (5-Count). As for another example, consider an even more stringent counting policy in Varzi (2010):

(A) An inventory of the world is to include an entity $x$ only if $x$ is mereologically atomic (Varzi, 2010: 300).

\footnotetext{
32 One may even try to respond that the arguments by endorsing a somewhat Fregean notion of counting. According to such broadly Fregean notion we never count objects simpliciter but only under certain sortals $F, G$, and so on. That is, we always count how many $F$-s or $G$-s there are. I am not going to consider this strategy on behalf of universalists here, for two reasons. First, I remain unconvinced that there is a robust notion of sortal to which we can always appeal. Second it is not difficult to envisage some sortals that apply to all the objects in a given world $w$ so that the argument could still be run using those sortals.

33 See also Varzi (2014).

34 For a critique see Berto and Carrara (2009).
} 
It should be clear that universalism is not in any tension with the claim there is a possible world $w$ such that, under the counting policy in (A), counting the objects in $w$ results in a count of exactly $n$ objects. This is because, according to (A), one should count only atoms. And clearly, the problems for universalists are due to their countenancing the existence of composite objects. In either case, the way out of the Possibility Arguments is to note that there is a reading of (5), namely (5-Count), according to which universalists can indeed accomodate the relevant pre-theoretical intuition. As a matter of fact, the right thing to say in these circumstances would be that the Incompatiblity Premise is false-more on this in a second.

Finally, I want to argue that, if (5) is read as (5-Existence), then universalists have all the rights to simply discard the alleged pre-theoretical intuition. (5-Existence) is supposed to cash out a pre-theoretical intuition about a purely quantificational notion of existence. According to universalists, we quantify over both parts and wholes, that is, things that are built up from parts according to some specific laws of composition. If so, it should be granted that the relevant laws of composition play a crucial role in matter of existence. Any pre-theoretical intuition, such as the one at hand, that disregards completely such laws of composition can hardly be thought to carry any decisive weight. The result is that if (5) is read as (5-Existence), the pre-theoretical defense of the Possibility Premise is hardly compelling. To put it differently: it is hard to establish whether the alleged pre-theoretical intuition that underpins the Possibility Premise (5) is a pre-theoretical intuition about existence (5-Existence) or counting (5-Count). In the latter case, the Incompatibility Premise (4) is false. In the former case, universalists can — and should—-simply discard the Possibility Premise (5) itself. ${ }^{35}$

The conclusion I want to draw is the following. Insofar as the only arguments in favor of the Possibility Premise of the Contingentist Arguments are the ones I explored in the paper, ${ }^{36}$ I think universalists are in good shape. They can claim that that the universe has to be odd.

Acknowledgements For comments and suggestions on previous drafts of the paper I would like to thank Robert Michels, Achille Varzi, and Lisa Vogt. I also would like to thank two anonymous referees for this journal for their insightful suggestions which improved the paper greatly. This work has been funded by the Swiss National Science Foundation (SNF), Project Number PCEFP1_181088.

Funding Open Access funding provided by Université de Genève.

Open Access This article is licensed under a Creative Commons Attribution 4.0 International License, which permits use, sharing, adaptation, distribution and reproduction in any medium or format, as long as you give appropriate credit to the original author(s) and the source, provide a link to the Creative Commons licence, and indicate if changes were made. The images or other third party material in this article are included in the article's Creative Commons licence, unless indicated otherwise in a credit line to the material. If material is not included in the article's Creative Commons licence and your intended use is not permitted by statutory regulation or exceeds the permitted use, you will need to obtain permission directly from the copyright holder. To view a copy of this licence, visit http://creativecommons.org/licen ses/by/4.0/.

\footnotetext{
35 Thanks to two anonymous referees for this journal.

36 And I don't want to suggest these are in fact the only arguments. There are e.g. physics-based arguments against the very truth-let alone the necessity-of universalism. See e.g. Balashov (2010) and Caulton (2015). Not to mention the reservations against universalism mentioned in footnote 4.
} 


\section{References}

Balashov, J. (2010). Persistence and spacetime. Oxford: Oxford University Press.

Baxter, D., \& Cotnoir, A. (Eds.). (2014). Composition is identity. Oxford: Oxford University Press.

Berto, F., \& Carrara, M. (2009). To exist and to count. A note on the Minimalist View. dialectica, 63(3), 343-356.

Berto, F., \& Shoonen, T. (2018). Conceivability and possibility: Some dilemmas for humeans. Synthese, $195,2697-2715$.

Black, M. (1952). The identity of indiscernibles. Mind, 61, 153-164.

Bohn, E. (2009a). An argument against the necessity of unrestricted composition. Analysis, 69, $27-31$.

Bohn, E. (2009b). Must there be a top level? The Philosophical Quarterly, 39, 193-201.

Bohn, E. (2010). The necessity of universalism versus the possibility of junky worlds: A rejoinder. Analysis, 70, 296-298.

Calosi, C. (2016). Composition is identity and mereological nihilism. The Philosophical Quarterly, 66, $219-235$.

Calosi, C. (2018). Failure or boredom. The pendulum of composition as identity. American Philosophical Quarterly, 55(3), 281-292.

Caulton, A. (2015). Is mereology empirical? In T. Bigaj \& C. Wuthrich (Eds.), Metaphysics in contemporary physics (pp. 293-322). Brill: Rodopi.

Chalmers, D. (2002). Does conceivability entail possibility? In T. Gendler \& J. Hawthorne (Eds.), Conceivability and possibility (pp. 145-199). Oxford: Oxford University Press.

Comesaña, J. (2008). Could there be exactly two things? Synthese, 162, 31-35.

Cameron, R. P. (2007). The contingency of composition. Philosophical Studies, 136, 99-121.

Contessa, G. (2012). The junk argument: Safe disposal guidelines for mereological universalists. Analysis, 72, 455-457.

Cotnoir, A. J. (2014). Universalism and junk. Australasian Journal of Philosophy, 92, 649-664.

Cotnoir, A., \& Varzi, A. (Forthcoming). Mereology. Oxford: Oxford University Press.

Fiocco, O. (2007). Conceivability, imagination, and modal knowledge. Philosophy and Phenomenological Research, 74(2), 364-380.

Gendler, T., \& Hawthorne, J. (Eds.). (2002). Conceivability and possibility. Oxford: Oxford University Press.

Hill, C. (2016). Conceivability and possibility. In H. Cappelen, T. Szabo-Gendler, \& J. Hawthorne (Eds.), The Oxford handbook of philosophical methodology (pp. 326-347). Oxford: Oxford University Press.

Kung, P. (2010). Imagining as a guide to possibility. Philosophy and Phenomenological Research, 81(3), $620-663$.

Lewis, D. (1991). Parts of classes. Oxford: Blackwell.

Michels, R. (2020). Correct conceivability and its role in the epistemology of modality. In A. Declos \& J. Guillon (Eds.), Les principes métaphysiques. Paris: Collège de France.

Miller, K. (2009). Defending contingentism in metaphysics. dialectica, 63(1), 23-49.

Paivio, A. (1986). Mental representations. Oxford: Oxford University Press.

Parsons, J. (2013). Conceptual conservatism and contingent composition. Inquiry, 56(4), 327-339.

Putnam, H. (1994). Words and life. Cambridge: Harvard University Press.

Rosen, G. (2006). The limits of contingency. In F. MacBride (Ed.), Identity and modality (pp. 13-40). Oxford: Oxford University Press.

Schaffer, J.(2003). Is there a Fundamental Level? Nô̂s, 37(3), 498-517.

Schaffer, J. (2017). Laws for metaphysical explanations. Philosophical Issues, 27, 302-321.

Simons, P. (1987). Parts. A study in ontology. Oxford: Oxford University Press.

Smith, D. (2019). Gunky objects, junky worlds, and weak mereological universalism. Erkenntnis, 84, 41-55.

Sorensen, R. (2003). A brief history of paradox. Oxford: Oxford University Press.

van Inwagen, P. (1998). Modal epistemology. Philosophical Studies, 92, 67-84.

Varzi, A. (2009). Universalism entails extensionalism. Analysis, 69(4), 599-604.

Varzi, A. (2010). Mereological commitments. dialectica, 54(4), 283-305.

Varzi, A. (2014). Counting and countenancing. In D. Baxter \& A. Cotnoir (Eds.), Composition as identity (pp. 47-69). Oxford: Oxford University Press.

Varzi, A. (2016). Mereology. Stanford encyclopedia of philosophy. https://plato.stanford.edu/archives/ spr2019/entries/mereology/\#toc. 
Vogt, L. \& Werner, J. (MS). Countable composition.

Watson, D. (2010). An argument against an argument against the necessity of universal mereological composition. Analysis, 70(1), 78-82.

Yablo, S. (1993). Is conceivability a guide to possibility? Philosophy and Phenomenological Research, 53, $1-42$.

Publisher's Note Springer Nature remains neutral with regard to jurisdictional claims in published maps and institutional affiliations. 